\title{
Pharmacy Practice Residencies in Canada: Opportunities and Emerging Challenges
}

\author{
Peter J Zed
}

$\mathrm{F}$ or more than 4 decades, 1-year pharmacy residency programs have been the primary post-baccalaureate training path for pharmacists interested in pursuing a career in hospital practice. The Canadian Hospital Pharmacy Residency Board (CHPRB) defines a residency in pharmacy practice as "an organized, directed and accredited program that builds upon competencies of an accredited pharmacy professional degree program. The pharmacy practice residency focuses on direct patient care, pharmacy operations, project management and personal aspects of pharmacy practice." Graduates of current baccalaureate pharmacy programs are not prepared to function independently in today's hospital pharmacy environment, where pharmacists must provide direct patient care and meet the expectations of a rapidly changing scope of practice. Although existing pharmacy practice residency programs differ in scope and activities, these programs bridge the gap in knowledge and experience between undergraduate training and hospital pharmacy practice, and pharmacists who have completed a residency are better prepared to enter hospital practice.

As pharmacy practice has continued to evolve, so have the expectations placed on pharmacists who practise in the hospital setting. More than ever before, hospital pharmacists are being given opportunities to function to the full extent of their scope of practice, which means that greater expectations are placed on those pharmacists who have completed a pharmacy practice residency program. Some have challenged the approach and duration of post-baccalaureate training to prepare pharmacists to practise in the hospital setting, with the result that several 24-month (instead of 12-month) pharmacy practice programs now exist in the United States. ${ }^{2}$ The American Society of Health-System Pharmacists and the American College of Clinical Pharmacy both describe a 24-month residency in pharmacotherapy as "one designed to produce a specialized practitioner with the ability to deliver pharmaceutical care to diverse inpatient and outpatient populations presenting with varied and complex health problems."2 Postgraduate year 1 (PGY1) enhances the resident's general competencies in managing medication use systems and supports optimal medication outcomes for patients with a broad range of disease states. Postgraduate year 2 (PGY2) is designed to increase the resident's depth of knowledge, skills, attitudes, and abilities and to raise the level of expertise in medication therapy

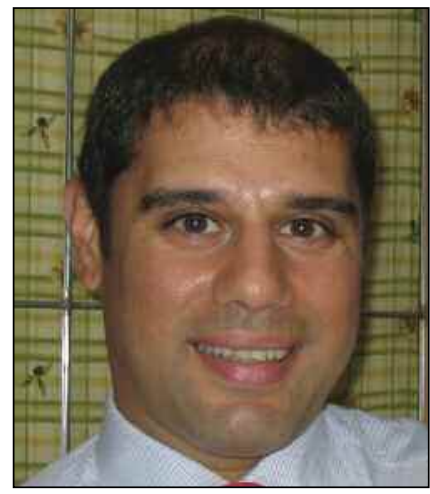
management and clinical leadership. It is believed that those who have completed the first year of a 2-year postgraduate program, similar to the graduates of all programs in Canada, are minimally competent to provide general services but, in many cases, are still not prepared to independently assume responsibility for the more complex decision-making involved in the selection and management of drug therapy. ${ }^{3}$ The PGY2 allows residents to develop more in-depth knowledge by working in specialized and differentiated areas of practice.

The CSHP 2015 initiative, with a target date that is now just 6 years away, has set out some very important goals and objectives for pharmacy practice in hospitals and related health care settings. ${ }^{4}$ Pharmacists are challenged to increase the extent to which patients achieve best use of medications, to actively apply evidence-based methods to improve medication therapy, to improve the safety of medication use, to effectively apply technology, and to engage in public health initiatives on behalf of their communities. One of the initiative's objectives states that by 2015 all new pharmacists entering practice in a hospital or related health care setting will have completed a CHPRBaccredited pharmacy practice residency. This objective is a clear acknowledgement that the expectations and ever-changing scope of practice in hospitals and related health care settings now requires additional training beyond completion of an undergraduate pharmacy degree. Although some variation in 
ability to meet this objective is to be expected, I suspect that most Canadian hospitals and related health care settings would fail to meet this objective today.

In this issue of CJHP, the authors of our Point Counterpoint offer 2 perspectives on the optimal duration of a pharmacy practice residency in Canada. ${ }^{5.6}$ The authors describe the advantages and disadvantages of a 24-month program, given the current practice environment, scope of pharmacist practice, and evolving trends in pharmacy education in Canada. However, consideration of our current and future ability to train pharmacy practice residents in Canada should not be lost in our discussion of this important issue. The evolution of pharmacy education in Canada and further expansion of the hospital pharmacist's scope of practice will continue to shape hospital pharmacy residency programs in both duration and scope. Even so, the debate on the duration of pharmacy practice residency programs in Canada should not overshadow the bigger, and arguably more important, challenge of training enough pharmacists in accredited pharmacy practice residencies to meet the CSHP 2015 objective.

Issues in many facets of health care are developing at a rapid pace, and all health care providers face more challenges than ever before. Pharmacists must embrace these changes and rise to the challenges of today's health care environment, beginning with their preparation to practise. Regardless of the duration of a pharmacy practice residency program, hospitals, health regions, universities, and the CHPRB must first work together to determine how we can train enough hospital pharmacists in Canada and how we can enable these highly skilled professionals to function within their full scope of practice. We owe it to our profession and, more important, to our patients.

\section{References}

1. Canadian Society of Hospital Pharmacists, Canadian Hospital Pharmacy Residency Board. Accreditation standards: January 2010 [Internet]. Ottawa (ON): Canadian Society of Hospital Pharmacists: 2009 [cited 2009 Feb 11]. Available from: http://www.cshp.ca/programs/residencyTraining/CHPRB_ Standards_2010_-_FINAL.pdf (membership required to access content).

2. Nappi J, Haase K, Kessels A, Fink J. What is a pharmacotherapy residency? Benefits of a 24-month program [editorial]. Pharmacotherapy 2008;28(7): 819-820.

3. American College of Clinical Pharmacy; Burke JM, Miller WA, Spencer AP, Crank CW, Adkins L, Bertch KE, et al. Clinical pharmacist competencies. Pharmacotherapy 2008;28(6):806-815.

4. CSHP 2015-a practice excellence initiative for pharmacists in hospitals and related healthcare settings [Internet]. Ottawa $(\mathrm{ON})$ : Canadian Society of Hospital Pharmacists; 2007 [cited 2008 Nov 27]. Available from: http://www.cshp.ca/programs/cshp2015/index_e.asp

5. Woloschuk D. Is a 1-year residency program long enough to prepare hospital pharmacists for practice? The "pro" side. Can J Hosp Pharm 2009;62(1):43-44.

6. Yuksel $\mathrm{N}$, Hughes $\mathrm{C}$. Is a 1-year residency program long enough to prepare hospital pharmacists for practice? The "con" side. Can J Hosp Pharm 2009;62(1):44-45.

Peter J Zed, BSC, BSC(Pharm), ACPR, PharmD, FCSHP, is Clinical Coordinator, Department of Pharmacy, and Pharmacotherapeutic Specialist-Emergency Medicine, Queen Elizabeth II Health Sciences Centre, and Associate Professor, College of Pharmacy and Department of Emergency Medicine, Dalhousie University, Halifax, Nova Scotia. He is also an Associate Editor with CJHP.

Address correspondence to:

Dr Peter J Zed

Department of Pharmacy—Halifax Infirmary

Queen Elizabeth II Health Sciences Centre

1796 Summer Street

Halifax NS

$\mathrm{B} 3 \mathrm{H} 3 \mathrm{~A} 7$

e-mail: peter.zed@dal.ca 